\title{
Connecting experiences with heterosexism and sexual behavior in a sample of ethnically diverse sexual minority
}

\section{men}

\author{
Erin R. Smith and Paul B. Perrin* \\ Virginia Commonwealth University, USA
}

\begin{abstract}
This study examined associations between heterosexist experiences and sexual behaviors in sexual minority men (SMM). Ethnically diverse cis-gender SMM completed a national online survey assessing experiences with heterosexism and various sexual behaviors they had engaged in over the past year. High reported rates of a number of sexual behaviors over the past 6 months emerged: left social event with someone (46.1\%), sexual behavior with an acquaintance (63\%), regretted sexual encounter (55\%), fellatio without a condom (80.9\%), anal sex without a condom (62.9\%), analingus without protection (57.3\%), sex with uncommitted partners (61.8\%), sex under the influence of substances (60.7\%), and sex before discussing risk factors (53.9\%). A canonical correlation found that experiences with heterosexism and sexual behaviors had 25\% overlapping variance. The standardized canonical coefficients suggested that SMM who have experienced high levels of work/school and other discrimination report a larger intent to engage in sexual acts. Multiple regressions showed that harassment/rejection, work/school, and other heterosexism significantly explained $19.5 \%$ of the variance in intent to engage in sexual acts and $12.2 \%$ of the variance in impulsive sexual acts, with work/school heterosexism being a unique predictor of the intent to engage in sexual acts. Experiences with heterosexist discrimination were robustly associated with sexual behavior, suggesting that some SMM may use sexual behavior as a method of coping with discrimination. Interventions that help SMM become aware of this possible link in their own life and identify more effective coping strategies may be particularly valuable.
\end{abstract}

\section{Introduction}

Sexual behaviors may be an important health concern for sexual minority men (SMM). Despite the known risks of some of these behaviors, particularly unprotected anal intercourse (e.g., STIs, HIV/AIDS), SMM have been shown to engage in high rates of these sexual behaviors [1]. For example, rates of unprotected anal sex are increasing, with $57 \%$ of men who have sex with men reporting at least one incidence of unprotected anal sex in the past year in 2011, while only $48 \%$ reported unprotected anal sex in the past year in 2005 [2]. The literature on sexual behavior in SMM has traditionally focused on risk factors including substance abuse and outcomes such as HIV, while only a smaller line of research has examined how macro-level variables such as discrimination due to sexual minority status may predict sexual behaviors in SMM.

Sexual minority individuals are frequently targets of traumatic discriminatory acts. Mays and Cochran [3] found that over 75\% of lesbian, gay, bisexual, and transgender (LGBT) individuals have experienced discrimination at some point in their lifetime, while another study found $21.4 \%$ of LGBT individuals experienced discrimination in the past year [4]. SMM in particular experience more frequent hate crimes [5], weapon assault [6], sexual victimization [6-7], and are followed more than sexual minority women [6].

Bennett et al. [8] have argued that in order to cope with traumatic discriminatory experiences and the stress that stems from these experiences, individuals may engage in health risk behaviors, such as sexual behaviors. Others have theorized that discriminatory experiences may be associated with decreases in self-control [9], which may lead to greater participation in risky behaviors. Although some types of discrimination (e.g., racism) have been associated with sexual behaviors [10], studies that have examined heterosexism and sexual behavior in SMM have traditionally focused on unprotected anal intercourse (e.g., [11,12]), despite studies indicating SMM may also engage in sexual behaviors such as unprotected vaginal intercourse [1].

One study examining sexual minority youth found that those experiencing the highest rates of victimization were more likely to engage in sexual behaviors than their heterosexual counterparts [13]. Similarly, oppression (heterosexism, racism, and poverty/financial hardship) has been associated with unprotected anal intercourse in Latinos and Black men [14-16]. However, the aforementioned studies solely examined unprotected anal intercourse. SMM may engage in other sexual behaviors, including sex with uncommitted partners, impulsive sexual behaviors, and other sexual acts (e.g., oral sex) that are associated with STI status that have not been previously linked to discriminatory experiences.

\section{Present study}

Despite the high frequency in which research has shown SMM engage in sexual behaviors and the negative potential health outcomes

Correspondence to: Paul B. Perrin, Ph.D., Assistant Professor, Department of Psychology, Virginia Commonwealth University, 808 West Franklin St., Room 201, P.O. Box 842018, Richmond, VA 23284-2018, USA, Tel: (804) 827-3894; Fax: (804) 828-2237; E-mail: pperrin@vcu.edu

Key words: LGBTQ issues, Sex

Received: August 07,2017; Accepted: August 14, 2017; Published: August 21, 2017 
associated with these behaviors, the majority of research in SMM has focused solely on unprotected anal intercourse and risk factors such as substance abuse and HIV. The purpose of the present study was to examine how discriminatory experiences (heterosexism) are associated with unprotected anal intercourse as well as numerous additional indices of sexual behavior, including intention to engage in sexual behaviors, impulsive sexual behaviors, sexual acts, and sexual behaviors with uncommitted partners.

\section{Method}

\section{Participants}

The sample consisted of cis-gender men from the United States ( $\mathrm{n}$ = 89) who identified as gay (60.7\%), bisexual (25.8\%), queer (11.2\%), or an "other" non-heterosexual sexual orientation (2.2\%). The average age of participants was 30.76 years $(\mathrm{SD}=10.30)$, with a range from 19 to 62 years. The sample was $28.1 \%$ White/European-American, $27 \%$ Asian/Asian-American/Pacific Islander, 22\% Black/African American (non-Latino), 10.1\% Multiracial/Multiethnic, 7.9\% Latino/Hispanic, and $4.5 \%$ American Indian/Native American.

\section{Materials}

\section{Heterosexism}

Participants' heterosexist experiences were assessed with the Heterosexist Harassment, Rejection, and Discrimination Scale [17]. The measure consists of three subscales: harassment/rejection, workplace/school, and other heterosexism. This scale has been shown to have strong internal consistency $(\alpha=.90)$.

\section{Sexual behavior}

Sexual behavior was assessed using the Sexual Risk Survey (SRS; [18]). This measure consists of 23 items across 5 subscales that assess sexual behavior with uncommitted partners, sex acts, impulsive sexual behaviors, intent to engage in sexual behaviors, and anal sex acts in the past six months. Overall, the scale has high internal consistency $(\alpha=$ $.88)$, as do each of the five subscales of uncommitted partners $(\alpha=.88)$, sex acts $(\alpha=.80)$, impulsive sexual behaviors $(\alpha=.78)$, intent to engage in sexual behaviors, $(\alpha=.89)$, and anal sex acts $(\alpha=.61 ;[18])$.

Items from the SRS were recoded into five categories from 0 - 4 as recommended by Turchick and Garske [18]. Responses of 0 for the frequency of any item were coded as " 0 ." All frequencies greater than 0 were analyzed as if they represented $100 \%$ of responses. To categorize the remaining responses, the following recommendations by Turchick and Garske [18] were followed: $1=40 \%, 2=30 \%, 3=$ $20 \%$, and $4=10 \%$. Due to the varying frequencies in many of these items, an attempt was made to adhere as closely to these guidelines as possible. Through this process, participants who reported a frequency (e.g., 1), were put into a category. If the next group of participants (e.g., those who reported a frequency of 2) exceeded the threshold of the previous group (e.g., 40\%) coded as "1," they were moved to the next category, "2," and so on.

\section{Procedure}

Online national and regional organizations, community groups, and forums that cater to sexual minority individuals were contacted by the researchers via email and were given information on the present study. An effort was made to recruit an ethnically diverse sample by contacting groups, forums, and organizations that cater to ethnically diverse sexual minority individuals. Interested individuals were screened by the study coordinator via email, who then confirmed the individual self-identified as a sexual minority individual. Once approved for participation, participants were emailed a link to the survey as well as a unique code to receive compensation for participation (a $\$ 15$ gift card to amazon.com). Informed consent was obtained from each participant before they began the survey.

\section{Results}

\section{Frequencies of sexual behaviors in the past 6 months}

Frequencies of behaviors in the past 6 months for each of the 23 items from the SRS are listed in Table 1. In the sample, only $10.1 \%$ of participants reported not having had a sexual partner in the past 6 months. Almost half reported seeking out sexual experiences. Sex with uncommitted partners (e.g., not in a monogamous relationship, or with someone they do not know well) was reported in over half of participants. Similarly, sexual partners who have had many past partners and partners with other current partners were reported by over half of participants. The majority of participants reported impulsive sexual behaviors, including regrettable and unexpected sexual experiences, and sex with an acquaintance. Vaginal sexual behaviors were not frequently reported in this sample, likely due to the majority of participants identifying as gay. However, anal sex acts, including anal sex and analingus without condoms or protection, were reported by over half of participants.

\section{Bivariate correlations}

A correlation matrix was created to examine bivariate relationships among heterosexism and sexual behavior (Table 2). Sexual acts were positively related to work/school heterosexism. Impulsive sexual behaviors were positively related to work/school and other heterosexism. Intent to engage in sexual acts was positively related to harassment/rejection, work/school, and other heterosexism. And anal sex acts was positively related to work/school and other heterosexism.

Table 1. Percentage of responses according to category.

\begin{tabular}{|l|l|l|l|}
\hline Item & $\mathbf{\%}>\mathbf{0}$ & Median of $>\mathbf{0}$ & SD of $>\mathbf{0}$ \\
\hline 1. Number of behavioral sexual partners & 78.7 & 3 & 2.11 \\
\hline 2. Left social event with someone & 46.1 & 2 & 1.23 \\
\hline 3. Sexual behavior with acquaintance & 63 & 2 & 2.45 \\
\hline 4. Intent of sexual behavior & 47.2 & 2.5 & 15.17 \\
\hline 5. Intent of engaging in sex & 47.2 & 3 & 15.16 \\
\hline 6. Unexpected sexual experience & 65.2 & 2.5 & 5.26 \\
\hline 7. Regretted sexual encounter & 55 & 2 & 2.06 \\
\hline 8. Number of sex partners & 89.9 & 4 & 111.81 \\
\hline 9. Vaginal sex without a condom & 24.7 & 3.5 & 11.71 \\
\hline 10. Vaginal sex without birth control & 15.7 & 3.5 & 4.23 \\
\hline 11. Fellatio without a condom & 80.9 & 8.5 & 121.7 \\
\hline 12. Cunnilingus without protection & 27 & 5 & 9.46 \\
\hline 13. Anal sex without a condom & 62.9 & 4 & 133.29 \\
\hline 14. Unprotected anal penetration & 28.1 & 3.5 & 4.15 \\
\hline 15. Analingus without protection & 57.3 & 3 & 6.78 \\
\hline 16. Sex with uncommitted partners & 61.8 & 3 & 5.05 \\
\hline 17. Sex with someone didn't know well & 64 & 2 & 11.29 \\
\hline 18. Sex under the influence of substances & 60.7 & 3 & 12.3 \\
\hline 19. Sex before discussing risk factors & 53.9 & 3 & 7.5 \\
\hline 20. Partners with many past partners & 61.8 & 3 & 7.48 \\
\hline 21. Sex with untested partners & 36 & 2 & 8.67 \\
\hline 22. Sex with partner didn't trust & 41.6 & 2 & 3.68 \\
\hline 23. Partners with other current partners & 53.9 & 3 & 7.92 \\
\hline & & & \\
\hline
\end{tabular}




\section{Canonical correlation}

To measure the relationship between heterosexism and sexual behavior, a canonical correlation was performed. Canonical correlation analyzes the relationships between two sets of variables; in the current study, heterosexism (harassment/rejection, work/school, and other) and the sexual behavior (sex with uncommitted partners, sex acts, intent to engage in sexual behavior, impulsive sex acts, and anal sex acts). The first canonical correlation was .50 (25\% overlapping variance), $\lambda=.696, \chi^{2}(15)=30.24, p=.011$, which is considered a large effect size according to Cohen's standards [19]. The second canonical correlation was .28 ( $7.7 \%$ overlapping variance), $\lambda=.922, \chi^{2}=(8) 6.77$, $p=.562$. The third canonical correlation was $.03(.000676 \%$ of the overlapping variance), $\lambda=.999, \chi^{2}=(3) 0.55, p=.997$. The second and third canonical correlations were not statistically significant; therefore they will not be interpreted further.

Standardized canonical correlations were calculated to compare the contributions of each variable to the overall first canonical correlation (Figure 1). The standardized coefficients for the heterosexism variables showed that work/school heterosexism (-.717) had the largest loading, followed by other heterosexism (-.485). The standardized canonical coefficients for sexual behavior showed that intent to engage in sexual behaviors had the largest loading (-.743). All of the other variables loaded below the conventional cutoff of .40. These results suggest that individuals who had experienced work/school and other heterosexism reported greater intention of engaging in sexual behaviors.

\section{Multiple regressions}

Five simultaneous multiple regressions were conducted to examine if harassment/rejection, work/school, and other heterosexism significantly predicted sexual behavior. The first regression that included sexual acts with uncommitted partners as the criterion variable was not significant $[F(3,85)=1.155, p=.332]$. The second regression with sexual acts as the criterion variable was also not statistically significant $[F(3,85)=2.557, p=.061]$. The third regression explained $12.2 \%$ of the variance impulsive sexual behaviors $[F(3,85)=3.951, p$ $=.011]$, although harassment $/$ rejection $[\beta=-.061, p=.663]$, work $/$ school $[\beta=.247, p=.077]$ and other $[\beta=.180, p=.227]$ heterosexism were not unique predictors. The fourth regression explained $19.5 \%$ of the variance in intent to engage in sexual acts $[F(3,85)=6.859, p<$ $.001]$; work/school was a unique predictor $[\beta=.337, p=.013]$, although harassment $/$ rejection $[\beta=-.064, p=.634]$ and other $[\beta=.190, p=.183]$ heterosexism were not. The fifth regression with anal sex acts as the criterion variable was not statistically significant $[F(3,85)=1.948, p=.128]$.

Table 2. Sexual behaviors as bivariate correlations

\begin{tabular}{|c|c|c|c|c|c|c|}
\hline & $\begin{array}{l}\text { Harassment/ } \\
\text { Rejection }\end{array}$ & & $\begin{array}{l}\text { Work/School } \\
\text { Heterosexism }\end{array}$ & & Other Heterosexism & \\
\hline & $r$ & $p$-value & $r$ & $p$-value & $r$ & $p$-value \\
\hline Uncommitted Partners & 0.037 & 0.734 & 0.179 & 0.093 & 0.088 & 0.412 \\
\hline Risky Sexual Acts & 0.049 & 0.651 & 0.258 & $.015^{*}$ & 0.131 & 0.223 \\
\hline Impulsive Sexual Behaviors & 0.201 & 0.058 & 0.327 & $.002 *$ & 0.299 & $.004 *$ \\
\hline Intent to Engage in Sexual Acts & 0.258 & $.015^{*}$ & 0.422 & $.001^{*}$ & 0.365 & $.001^{*}$ \\
\hline Risky Anal Sex Acts & 0.164 & 0.125 & 0.224 & 0.035 & 0.235 & $.027 *$ \\
\hline
\end{tabular}

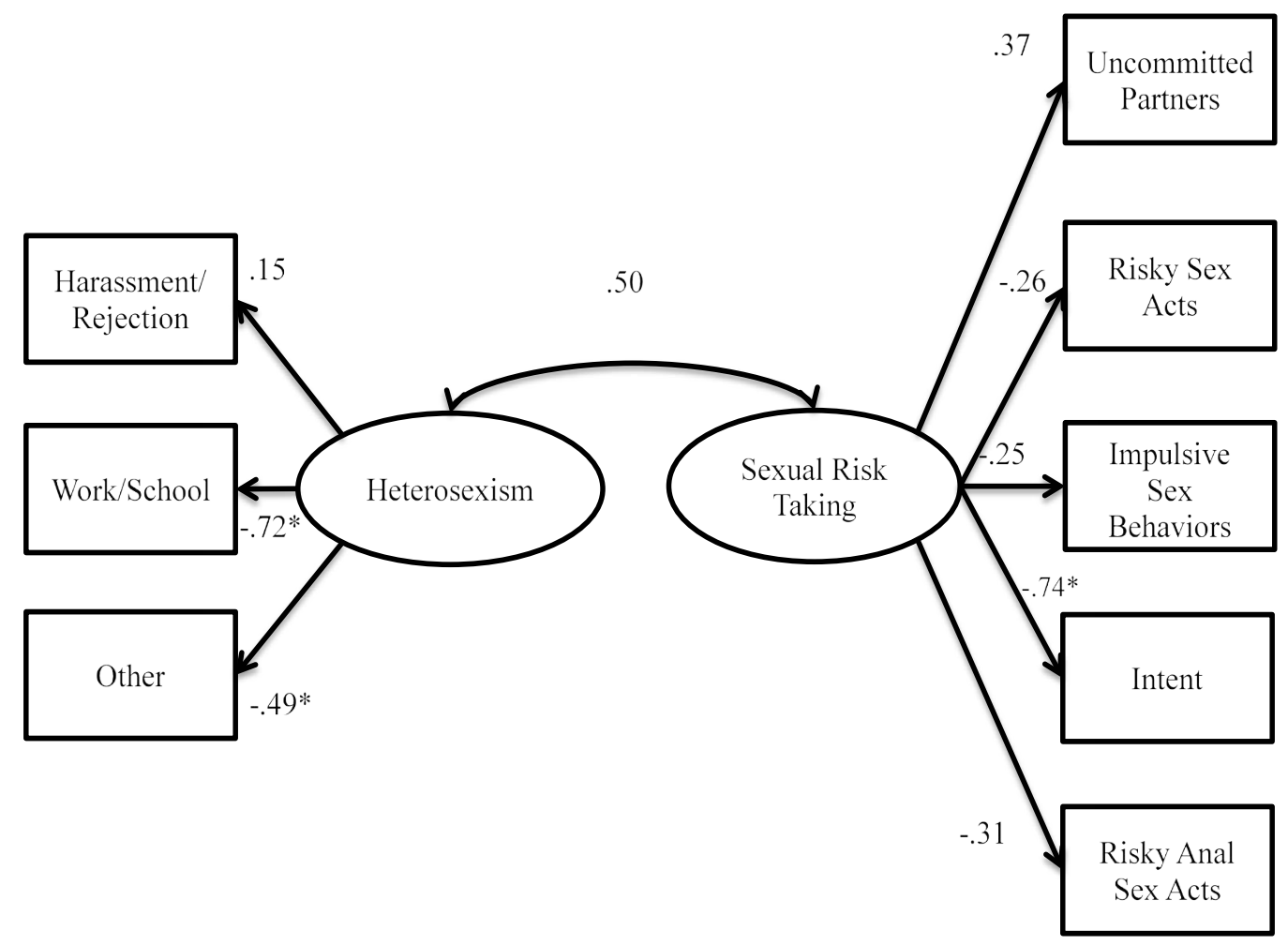

Figure 1. Canonical Correlation 


\section{Discussion}

\section{Frequencies of sexual behaviors in the past 6 months}

Intent to engage in sexual behaviors: Almost half of participants in the current study reported going out to bars, parties, or other social events with the intent of engaging in sexual behavior, or the intent of having sex with someone. Although the intention of engaging in sexual behaviors does not necessarily result in actual sexual behaviors, the current results suggest that the sample was frequently seeking out these opportunities. The theory of planned behavior [20] posits that an individual's intention to engage in a specific behavior does indeed predict the behavior, and therefore the intention to engage in sexual behaviors occurs before the behaviors. Although not all SMM who seek out sexual partners will be successful in all circumstances, the current results suggest that this sample frequently endorsed the intention to engage in sexual behavior which is an important predecessor to the actual behaviors. It is likely that factors such as being unable to find a willing sexual partner while seeking out sexual experiences may explain the low loadings of sexual behaviors in the current study, such as unprotected anal intercourse.

Impulsive sexual behaviors: Several impulsive sexual behaviors were frequently reported in the current sample: unexpected sexual experiences (65.2\%), regrettable sexual encounters (55.0\%), and leaving social events with someone they had just met by $(46.1 \%)$. Previous research has similarly demonstrated that the impulsive nature of certain sexual behaviors is a major issue for some men who have sex with men, as impulsivity has been predictive of unprotected anal intercourse with multiple partners, among other sexual behaviors in this population [21].

Sex with uncommitted partners: Engaging in sexual behaviors with uncommitted partners was frequently reported in the current sample. Over half of participants reported having sex with someone they know, but were not in a relationship with (i.e., dating, "friends with benefits"). Similarly, $64 \%$ of participants reported having sex with someone they either just met or do not know well at least once. Prestage [22] obtained similar results in SMM, with 57\% of participants reporting at least half of their casual sex partners being anonymous. Having sex with someone the participant knew has had many other sexual partners was also common in the current study, with $61.8 \%$ of participants doing so at least once. And over half reported having sex with a new sexual partner before discussing STI status, current sexual partners, sexual history, or intravenous drug use, as well as engaging in sexual behaviors with someone who was also engaging in sexual acts with others. Previous research has found that men who have sex with men are less likely to disclose HIV-positive status to casual partners or while using drugs [23], demonstrating that sexual behaviors with casual, uncommitted partners are likely a risk for harmful health outcomes.

Sex acts: Over three-quarters of participants reported either giving or receiving oral sex on a man without protection. High rates of unprotected oral sex in SMM have also been found in other studies [24]. However, participants reported relatively low rates of vaginal sex items, although almost a quarter of participants reported at least one incidence of unprotected vaginal sex, and $26.9 \%$ reported performing oral sex on a woman in the past six months. Further, $15.7 \%$ reported engaging in vaginal intercourse without protection against pregnancy at least once. These lower rates of sexual behaviors with women are not surprising, as the majority of participants self-reported their sexual orientation as gay. Indeed, Kashubeck-West \& Szymanski [1] reported that vaginal intercourse in their sample of predominantly gay men was "extremely infrequent." Similar to previous research in SMM [2527], use of alcohol and/or drugs before or during sex was frequently reported in the current sample.

Anal sex acts: Nearly two-thirds of participants reported unprotected anal sex, half unprotected analingus, and a quarter anal penetration with hands or objects without a condom prior to engaging in unprotected sex. Previous studies using online samples with men who have sex with men have reported varying but somewhat similar rates of unprotected anal sex (52\%, [28]). Gillmore et al. [29] found $82 \%$ of SMM had reported anal sex in the past 2 months, with $17 \%$ of SMM never using condoms, and $32 \%$ only using condoms sometimes. These high rates of anal behavior are generally consistent with literature documenting increases in rates of unprotected anal sex in SMM [2].

\section{Heterosexism and sexual behavior in SMM}

The canonical correlation showed that there was $25 \%$ overlapping variance between heterosexism and sexual behavior, which is considered a large effect size. There are several potential explanations for this overarching finding. As noted by Nakamura and Zea [30], experiences with traumatic homonegativity could result in lower selfefficacy, and in turn, using sexual behaviors a maladaptive coping strategy. Indeed, sexual behavior, especially unprotected anal sex with non-primary partners, has been associated with avoidance coping in SMM [28]. It has also been theorized by Shernoff [27] that internalized heterosexism may contribute to the unconscious notion that gay men are unimportant and not valuable, which could increase a sense of expendability in themselves or their sexual partners.

Within the overall canonical correlation, the finding that SMM who have experienced high levels of work/school discrimination reported a greater intent to engage in sexual acts mirrors the findings in the fourth multiple regression finding that the only unique predictor of intent was work/school discrimination. Previous research has found a relationship between disclosure of sexual minority orientation at work and perceived discrimination [31] and multiple studies on sexual minority youth show that they frequently experience discriminatory events in school settings due to their sexual orientation, particularly boys [13, 32, 33]. These two forms of institutional and interpersonal discrimination are significant problems for SMM, and the current study suggests that this may even be associated with intentions to engage in sexual behavior, again perhaps as a coping strategy.

Similarly, other discrimination, which in this context was comprised of that from people in the helping/service professions and strangers, contributed unique variance to the regression predicting the intent to engage in sexual behavior. This finding is in line with previous research showing that healthcare providers tend to prefer heterosexual patients to sexual minority patients [34], lending support to the belief that many gay men endorse of medicine in general being heterosexist and ignorant of issues regarding sexuality [35]. However, it is important to note that in the fourth multiple regression, other discrimination was not a significant predictor of intent to engage in sexual behavior, suggesting that this effect (which also emerged in the bivariate correlations) was generally eclipsed by work/school discrimination.

Interestingly, heterosexism was not associated with uncommitted partners, vaginal sex acts, or anal sex acts, despite several of these forms of behavior being frequently reported in the current sample. Martin et al. [28] found that SMM who engage in unprotected anal 
sex with non-primary partners reported the highest amounts of victimization, although there was not a unique effect of heterosexism on sexual behaviors with uncommitted partners in the current study. Previous research has also found that SMM with higher levels of internalized heterosexism are more isolated from the gay community [36], and therefore may actually have fewer opportunities to seek out potential sexual partners and engage in sexual behavior. Therefore, it is possible that SMM in the current sample who experienced the most discrimination may have had some of the highest internalized heterosexism, and therefore been some of the most isolated from the LGBT community, washing out some of the hypothesized relationships with sexual behavior.

Conversely, it is also possible that involvement in the gay community may be a risk factor for unprotected sex in SMM. Previous research has found that SMM who are engaged in the gay community primarily through bars or clubs are more likely to engage in HIV-risk behaviors, such as unprotected anal sex [37]. SMM may also become involved in the gay community to fulfill needs for emotional intimacy via sex with uncommitted partners, as a number of SMM report that committed partners in the gay community can be difficult to find [38].

\section{Clinical implications}

The present findings indicate that work/school and other heterosexism are particularly associated with the intent to engage in sexual behaviors, suggesting that preventative interventions may be needed to reduce the connection between these constructs. The large associations between heterosexism and the intent to engage in sexual behavior identified here point to the need for programming to help SMM who experience high levels of heterosexism utilize more adaptive coping strategies. One such intervention that may be adapted is the community popular leader intervention, which utilizes repeated selfreviews of risk behaviors to reduce certain sexual behaviors (e.g., unprotected anal intercourse; [39]). A self-review of heterosexism could also be integrated into this intervention as well, as adaptive coping strategies to deal with this particular form of stressor.

\section{Limitations and future directions}

Although the present study had an ethnically diverse sample, the sample size limited the ability to examine differences in sexual behaviors between racial/ethnic groups, and perhaps differential levels of heterosexism influencing sexual behavior. Researching sexual behaviors in diverse SMM is of great importance, as previous research has shown that African Americans are disproportionately affected by HIV [40]. Indeed, previous research has found that $32 \%$ of African Americans, $14 \%$ of Latinos, and $7 \%$ of Caucasian young gay males tested positive for HIV infection, despite the fact that all participants were recruited from the same social venue [41].

Due to the correlational nature of the data, causal interpretations regarding the relationship between heterosexism and sexual behavior are fraught with challenges. As noted by Newcomb and Mustanski [42], it is possible that other variables account for the relationship between heterosexism and sexual behaviors in SMM.

Despite these limitations, this study found that experiences with heterosexist discrimination were robustly associated with the intent to engage in sexual behavior, suggesting that some SMM may use sexual behavior as a method of coping with discrimination. Interventions that help SMM become aware of this possible link in their own life and identify more effective coping strategies may be particularly valuable.

\section{Funding}

The survey software for this study was funded by award number UL1TR000058 from the National Center for Research Resources.

\section{References}

1. Kashubeck-West S, Szymanski DM (2008) Risky sexual behavior in gay and bisexual men: internalized heterosexism, sensation seeking, and substance use. Couns Psychol 36 :595-614.

2. Centers for Disease Control and Prevention HIV testing and risk behaviors among gay, bisexual, and other men who have sex with men - United States (2013) Morb Mortal Wkly Rep 62: 985-962.

3. Mays VM, Cochran SD (2001) Mental health correlates of perceived discrimination among lesbian, gay, and bisexual adults in the United States. Am J Public Health 91:1869-1876. [Crossref]

4. McLaughlin KA, Hatzenbuehler ML, Keyes KM (2010) Responses to discrimination and psychiatric disorders among Black, Hispanic, female, and lesbian, gay, and bisexual individuals. Am J Public Health 100:1477-1484. [Crossref]

5. Herek GM (2009) Hate crimes and stigma-related experiences among sexual minority adults in the United States: prevalence estimates from a national probability sample. $J$ Interpers Violence 24:54-74. [Crossref]

6. Katz-Wise SL, Hyde JS (2012) Victimization experiences of lesbian, gay, and bisexual individuals: a meta-analysis. $J$ Sex Res 49:142-167. [Crossref]

7. Balsam KF, Rothblum ED, Beauchaine TP (2005) Victimization over the life span: a comparison of lesbian, gay, bisexual, and heterosexual siblings. J Consult Clin Psychol 73:477-487. [Crossref]

8. Bennett GG, Wolin KY, Robinson EL, Fowler S, Edwards CL. Perceived racial/ethnic harassment and tobacco use among African American young adults. Am J Public Health 95: 238-240. [Crossref]

9. Inzlicht M, McKay L, Aronson J (2006) Stigma as ego depletion: how being the target of prejudice affects self-control. Psychol Sci 17: 262-269. [Crossref]

10. Roberts ME, Gibbons FX, Gerrard M, et al. (2012) From racial discrimination to risky sex: prospective relations involving peers and parents. Dev Psychol 48: 89-102. [Crossref]

11. Preston DB, D'Augelli AR, Kassab CD, Starks MT (2007) The relationship of stigma to the sexual risk behavior of rural men who have sex with men. AIDS Educ Prev Off Publ Int Soc AIDS Educ 19: 218-230. [Crossref]

12. Dudley MG, Rostosky SS, Korfhage BA, Zimmerman RS (2004) Correlates of highrisk sexual behavior among young men who have sex with men. AIDS Educ Prev Off Publ Int Soc AIDS Educ 16: 328-340.

13. Bontempo DE, D'Augelli AR (2002) Effects of at-school victimization and sexua orientation on lesbian, gay, or bisexual youths' health risk behavior. $J$ Adolesc Health Off Publ Soc Adolesc Med 30: 364-374. [Crossref]

14. Díaz RM, Ayala G, Bein E (2004) Sexual risk as an outcome of social oppression: data from a probability sample of Latino gay men in three U.S. cities. Cultur Divers Ethnic Minor Psychol 10: 255-267. [Crossref]

15. Ayala G, Bingham T, Kim J, Wheeler DP, Millett GA (2012) Modeling the impact of social discrimination and financial hardship on the sexual risk of HIV among Latino and Black Men who have sex with men. Am J Public Health 102: S242-S249. [Crossref]

16. Jarama SL, Kennamer JD, Poppen PJ, Hendricks M, Bradford J (2005) Psychosocial, behavioral, and cultural predictors of sexual risk for HIV infection among Latino men who have sex with men. AIDS Behav 9: 513-523. [Crossref]

17. Szymanski DM (2006) Does internalized heterosexism moderate the link between heterosexist events and lesbians' psychological distress? Sex Roles 54: 227-234.

18. Turchik JA, Garske JP (2009) Measurement of sexual risk taking among college students. Arch Sex Behav 38: 936-948. [Crossref]

19. Cohen J (1988) Statistical Power Analysis for the Behavioral Sciences. 2nd ed. Hillsdale, NJ: Erlbaum.

20. Ajzen I (1985) From Intentions to Actions: A Theory of Planned Behavior. In: Kuh PDJ, Beckmann DJ, eds. Action Control. SSSP Springer Series in Social Psychology. Springer Berlin Heidelberg; 11-39.

21. Jones J, Sullivan PS (2015) Impulsivity as a risk factor for HIV transmission in men who have sex with men: a delay discounting approach. J Homosex 62: 588-603. [Crossref] 
22. Prestage G, Van De Ven P, Grulich A, Kippax S, McInnes D, Hendry O (2001) Gay men's casual sex encounters: discussing HIV and using condoms. AIDS Care 13: 277284. [Crossref]

23. Gorbach P, Galea J, Amani B, et al (2004) Don't ask, don't tell: patterns of HIV disclosure among HIV positive men who have sex with men with recent STI practising high risk behaviour in Los Angeles and Seattle. Sex Transm Infect 80: 512-517. [Crossref]

24. Page-Shafer K, Shiboski CH, Osmond DH, et al. (2002) Risk of HIV infection attributable to oral sex among men who have sex with men and in the population of men who have sex with men. AIDS Lond Englm 16: 2350-2352.

25. Mattison AM, Ross MW, Wolfson T, Franklin D, San Diego HIV Neurobehavioral Research Center Group (2001) Circuit party attendance, club drug use, and unsafe sex in gay men. J Subst Abuse 13: 119-126.

26. Woolf SE, Maisto SA (2009) Alcohol use and risk of HIV infection among men who have sex with men. AIDS Behav 13: 757-782. [Crossref]

27. Shernoff M (2006) Condomless sex: gay men, barebacking, and harm reduction. Soc Work 51: 106-113. [Crossref]

28. Martin JI, Alessi EJ (2010) Stressful events, avoidance coping, and unprotected anal sex among gay and bisexual men. Am J Orthopsychiatry 80: 293-301. [Crossref]

29. Gillmore MR, Morrison DM, Leigh BC, Hoppe MJ, Gaylord J, Rainey DT (2002) Does "high = high risk"? An event-based analysis of the relationship between substance use and unprotected anal sex among gay and bisexual men. AIDS Behav 6: 361-370.

30. Nakamura N, Zea MC (2010) Experiences of homonegativity and sexual risk behaviour in a sample of Latino gay and bisexual men. Cult Health Sex 12: 73-85. [Crossref]

31. Ragins BR, Cornwell JM (2001) Pink triangles: antecedents and consequences of perceived workplace discrimination against gay and lesbian employees. $J$ Appl Psychol 86: 1244-1261. [Crossref]

32. Almeida J, Johnson RM, Corliss HL, Molnar BE, Azrael D (2009) Emotional distress among LGBT youth: the influence of perceived discrimination based on sexual orientation. $J$ Youth Adolesc 38: 1001-1014. [Crossref]
33. D'Augelli AR, Grossman AH, Starks MT (2006) Childhood gender atypicality, victimization, and PTSD among lesbian, gay, and bisexual youth. $J$ Interpers Violence 21: 1462-1482. [Crossref]

34. Sabin JA, Riskind RG, Nosek BA (2015) Health care providers' implicit and explicit attitudes toward lesbian women and gay men. Am J Public Health 105: 1831-1841. [Crossref]

35. Beehler GP (2001) Confronting the culture of medicine: gay men's experiences with primary care physicians. J Gay Lesbian Med Assoc 5: 135-141.

36. Williamson IR (2000) Internalized homophobia and health issues affecting lesbians and gay men. Health Educ Res 15: 97-107.

37. Fergus S, Lewis MA, Darbes LA, Butterfield RM (2005) HIV risk and protection among gay male couples: the role of gay community integration. Health Educ Behav 32: 151-171.

38. Seal DW, Kelly JA, Bloom FR, Stevenson LY, Coley BI, Broyles LA (2000) HIV prevention with young men who have sex with men: what young men themselves say is needed. AIDS Care 12: 5-26. [Crossref]

39. NIMH Collaborative HIV/STD Prevention Trial Group (1999) Results of the NIMH collaborative HIV/sexually transmitted disease prevention trial of a community popular opinion leader intervention. J Acquir Immune Defic Syndr 54: 204-214.

40. Centers for Disease Control and Prevention (2013) HIV testing and service delivery among Blacks or African Americans - 61 health department jurisdictions, United States, 2013. Morb Mortal Wkly Rep 64: 87-90.

41. Valleroy LA, MacKellar DA, Karon JM, et al (2000) HIV prevalence and associated risks in young men who have sex with men. JAMA 284: 198-204. [Crossref]

42. Newcomb ME, Mustanski B (2011) Moderators of the relationship between internalized homophobia and risky sexual behavior in men who have sex with men: a meta-analysis Arch Sex Behav 40: 189-199. [Crossref]

Copyright: $(02017$ Smith ER. This is an open-access article distributed under the terms of the Creative Commons Attribution License, which permits unrestricted use, distribution, and reproduction in any medium, provided the original author and source are credited. 